\title{
Asymmetric Anionic Polymerization of 1-Phenyldibenzosuberyl Acrylate Affording Optically Active Polymer with Helical Conformation
}

\author{
Toshimitsu Tanaka, Shigeki Habaue, and Yoshio Okamoto* \\ Department of Applied Chemistry, School of Engineering, Nagoya University, \\ Chikusaku, Nagoya 464-01, Japan
}

(Received May 29, 1995)

\begin{abstract}
Asymmetric anionic polymerization of 1-phenyldibenzosuberyl acrylate (PDBSA) was performed in toluene using complexes of $N, N^{\prime}$-diphenylethylenediamine monolithium amide (DPEDA-Li) or 9-fluorenyllithium with chiral ligands, $(+)-(S)$-1-(2-pyrrolidinylmethyl)pyrrolidine, $(-)-(S)$-1,2-bis(2-methoxymethylpyrrolidin-1-yl)ethane, (-)-sparteine, and (+)-(2S,3S)-2,3-dimethoxy-1,4-bis(dimethylamino)butane $((+)$-DDB). The (+)-DDB-DPEDA-Li system afforded the polymer of the highest specific rotation $\left([\alpha]_{365}^{25}=-129^{\circ}\right.$ in $\left.\mathrm{CHCl}_{3}\right)$ and isotacticity $(m=0.62)$. Optical rotation of the polymerization system with the (+)-DDB-DPEDA-Li complex at $-78^{\circ} \mathrm{C}$ increased with time. The CD spectral pattern of the polymer was quite similar to that of the one-handed helical, optically active poly(triphenylmethyl methacrylate) (PTrMA). These results suggest that optical activity may be attributed to chiral conformation of the polymer chain produced through polymerization.
\end{abstract}

KEY WORDS 1-Phenyldibenzosuberyl Acrylate / Asymmetric Polymerization / Anionic Polymerization / Poly(acrylic ester) / Optically Active Polymer / Helix / 2,3-Dimethoxy-1,4-bis(dimethylamino)butane /

The helix is one of the most important and interesting polymer structures. The structure is chiral and therefore a one-handed helical polymer is optically active. ${ }^{1}$ Triphenylmethyl methacrylate (TrMA) gives a one-handed helical, optically active polymer (PTrMA, $[\alpha]_{\mathrm{D}}^{25}=+350 \sim+390^{\circ}$ ) by anionic polymerization with chiral anionic initiators, ${ }^{2}$ and the polymer can separate a variety of racemates as chiral stationary phases for high-performance liquid chromatography. ${ }^{3}$ The helical structure of PTrMA is maintained by sterical repulsion of bulky ester groups existing along the highly isotactic polymer chain. Recently, we reported the formation of the optically active poly(triphenylmethyl acrylate) (PTrA) possessing a partially helical conformation in the polymerization with chiral anionic initiators. ${ }^{4} \mathrm{We}$ also reported that 1-phenyldibenzosuberyl methacrylate (PDBSMA) gave a highly isotactic polymer $(m m>98 \%)$ not only by anionic polymerization with optically active initiators, but also by radical polymerization which affords a polymer with lower isotacticity for TrMA. ${ }^{5}$ High stereoregulation in the radical polymerization of PDBSMA seems to be based on the rigid structure of the ester group. Reported herein is the asymmetric anionic polymerization of 1-phenyldibenzosuberyl acrylate (PDBSA) affording an optically active polymer with conformational chirality.

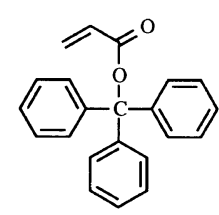

$\operatorname{TrA}$

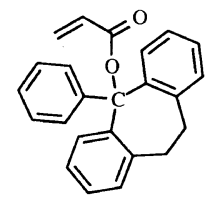

PDBSA

\footnotetext{
* To whom all correspondence should be addressed.
} 


\section{EXPERIMENTAL}

\section{Measurements}

${ }^{1} \mathrm{H}$ NMR spectra were measured on a Varian VXR-500S $(500 \mathrm{MHz})$ or Gemini-200 (200 $\mathrm{MHz}$ ) spectrometer in $\mathrm{CDCl}_{3}$ with tetramethylsilane as the internal standard. Infrared (IR) spectra were recorded on a JASCO FT/IR7000 spectrometer. Optical rotation was measured with a JASCO DIP-181 polarimeter. Circular dichroism (CD) spectra were obtained with a JASCO J-720 spectrometer. Gel permeation chromatographic (GPC) analysis was accomplished on a JASCO 880-PU equipped with UV and polarimetric (Shodex OR-1) detectors and on a JASCO BIP-1 equipped with an RI (JASCO 830-RI) detector using $\mathrm{CHCl}_{3}$ as the eluent. Two GPC columns TSK $\mathrm{G}_{4000 \mathrm{H}_{8}}$ and Shodex AC802.5 were connected in series. Molecular weight calibration curves were obtained with polystyrene standards.

\section{Materials}

Toluene was purified in the usual manner, mixed with a small amount of $n$-BuLi, and distilled under high vacuum just before use. Chiral ligands, (-)-sparteine ((-)-Sp) (Sigma), (+)-(2S,3S)-2,3-dimethoxy-1,4-bis(dimethylamino)butane $((+)$-DDB) (Aldrich), and $(+)$ $(S)$-1-(2-pyrrolidinylmethyl)pyrrolidine $((+)$ PMP) (Aldrich), were stirred with calcium hydride overnight and distilled under reduced pressure. (-)-(S)-1,2-bis(2-methoxymethylpyrrolidin-1-yl)ethane ((-)-BMPE) was synthesized by Colombo's method, ${ }^{6}$ dried on $\mathrm{LiAlH}_{4}$, and distilled just before use.

$N, N^{\prime}$-diphenylethylenediamine monolithium amide (DPEDA-Li) was prepared from $N, N^{\prime}$ diphenylethylenediamine with an equivalent amount of $n$-BuLi in toluene at room temperature.

PDBSA was synthesized from dibenzosuberone. Dibenzosuberone was converted into 1-phenyldibenzosuberol by reaction with phenyl magnesium bromide, and the sodium salt of the alcohol was reacted with acryloyl chloride in tetrahydrofuran (THF) to give the monomer: $\mathrm{mp} 129.5-130^{\circ} \mathrm{C}$; ${ }^{1} \mathrm{H}$ NMR $(200$ $\mathrm{MHz}, \delta, \mathrm{ppm}$ from tetramethylsilane (TMS) in $\left.\mathrm{CDCl}_{3}\right): 3.15\left(\mathrm{~s}, 4 \mathrm{H}, \mathrm{CH}_{2}\right), 5.87(\mathrm{dd}$, $1 \mathrm{H}, J=2.0,10.0 \mathrm{~Hz}$, vinyl), 6.27 (dd, $1 \mathrm{H}, J=$ $10.0,17.2 \mathrm{~Hz}$, vinyl), $6.45(\mathrm{dd}, 1 \mathrm{H}, J=2.0$, 17.2, vinyl), $7.0-7.5$ (m, 13H, aromatic); IR $\left(\mathrm{KBr}, \mathrm{cm}^{-1}\right.$ ) 1725, 1620, 1267, 1036, 756.

Elemental Analysis. Found: $\mathrm{C}=84.66 \%$; $\mathrm{H}=5.96 \%$. Calcd for $\mathrm{C}_{24} \mathrm{H}_{20} \mathrm{O}_{2}: \mathrm{C}=84.68 \%$; $\mathrm{H}=5.92 \%$.

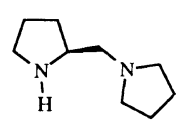

(+)-PMP

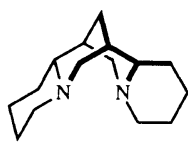

$(-)-\mathrm{Sp}$

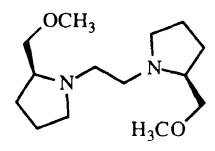

(-)-BMPE

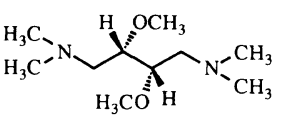

(+)-DDB

\section{Polymerization Procedure}

PDBSA $(0.50 \mathrm{~g}, 1.5 \mathrm{mmol})$ and toluene $(10 \mathrm{ml})$ were placed in a dry glass ampule under a dry nitrogen atmosphere, and the solution was cooled to $-78^{\circ} \mathrm{C}$. The initiator solution $(0.075 \mathrm{mmol})$, prepared by mixing DPEDA-Li ( 1 equiv) and chiral ligand (1.2 equiv) in toluene, was then added to the monomer solution with a syringe. After $24 \mathrm{~h}$, polymerization was terminated by adding a small amount of methanol. The products were poured into a large excess of methanol, collected by centrifugation immediately, and dried in vacuo at $60^{\circ} \mathrm{C}$ for $3 \mathrm{~h}$

Polymerization in a $1.0-\mathrm{cm}$ optical cell was carried out in the same manner and the change of optical rotation in the polymerization system at $-78^{\circ} \mathrm{C}$ was directly followed. The molecular weight and tacticity of the obtained polymer were determined by GPC and ${ }^{1} \mathrm{H}$ NMR analysis, ${ }^{7}$ respectively, of poly(methyl 
acrylate) (PMA) derived from the original PDBSA.

The obtained poly(PDBSA) was converted to PMA by hydrolysis in methanol containing a small amount of hydrochloric acid followed by methylation with diazomethane in the same manner as applied to poly(TrMA). ${ }^{2 f}$ The polymer was obtained almost quantitatively. ${ }^{8}$

\section{RESULTS AND DISCUSSION}

\section{Radical and Anionic Polymerization of PDBSA}

$\operatorname{TrA}$ forms a polymer with much less isotacticity in anionic polymerization as well as in radical polymerization in comparison with TrMA. ${ }^{9}$ Table I lists the results of radical and anionic polymerization of PDBSA in toluene, the stereoregularity of the obtained polymers, and the previous results ${ }^{4}$ on $\operatorname{TrA}$ for comparison. These monomers showed much lower isotacticities, in contrast with TrMA and PDBSMA which gave highly isotactic polymers even in the radical polymerization. ${ }^{5}$ The radical polymerization of PDBSA at $40^{\circ} \mathrm{C}$ afforded poly(PDBSA) in poor yield ( $5 \%$ ), and the isotacticity $(m=0.56)$ was a little higher than that of poly(TrA). On the other hand, in anionic polymerization by $n-\mathrm{BuLi}$ in toluene, the polymers were obtained in poor to moderate yields, and the effects of ester groups on the tacticity were opposite those in the radical polymerization.
Asymmetric Anionic Polymerization of PDBSA

Table II shows the results of the asymmetric anionic polymerization of PDBSA using the complexes of (+)-PMP, (-)-Sp, (+)-DDB, and (-)-BMPE with 9-fluorenyllithium (FlLi) and DPEDA-Li in toluene at $-78^{\circ} \mathrm{C}$. Some characteristic features of the polymerization are as follows. (1) The polymerization proceeded in fair to good yields in all cases. (2) DPEDA-Li seems to yield polymers of higher optical rotation than FlLi. (3) The bulky and rigid ester group, 1-phenyldibenzosuberylgroup, which is more effective in the polymerization of methacrylic esters than triphenylmethyl-group in producing a highly isotactic polymer, was ineffective for acrylic esters. (4) The tacticity and specific rotation of polymers were greatly affected by ligands; the (+)-DDBDPEDA-Li system afforded poly(PDBSA) of the highest specific rotation $\left([\alpha]_{365}^{25}=-94^{\circ}\right.$ in $\left.\mathrm{CHCl}_{3}\right)$ and isotacticity $(m=0.61)$, while the (+)-PMP-DPEDA-Li system was the most effective in the polymerization of $\operatorname{TrA}\left([\alpha]_{365}^{25}=\right.$ $+102^{\circ}$ in $\left.\mathrm{CHCl}_{3}, m=0.70\right)$. Therefore, the polymerization of PDBSA with the (+)-DDBDPEDA-Li system in toluene was fully investigated (Tables III and IV).

First, the effect of polymerization temperature was examined (Table III). The polymer yields were almost quantitative in all cases. The specific rotation of poly(PDBSA) depended on polymerization temperature. The polymer

Table I. Radical and anionic polymerization of TrA and PDBSA in toluene

\begin{tabular}{|c|c|c|c|c|c|c|c|c|}
\hline \multirow{2}{*}{ Entry } & \multirow{2}{*}{ Initiator } & \multirow{2}{*}[\mathrm{M}]{$/[\mathrm{II}]^{\mathrm{a}}$} & Temp & Time & Yield $^{b}$ & \multirow{2}{*}{$\mathrm{DP}_{n}{ }^{\mathrm{c}}$} & \multirow{2}{*}{$M_{w} / M_{n}^{\mathrm{c}}$} & \multirow{2}{*}{$\begin{array}{c}\text { Tacticity } \\
m: r\end{array}$} \\
\hline & & & ${ }^{\circ} \mathrm{C}$ & $\mathrm{h}$ & $\%$ & & & \\
\hline & \multicolumn{8}{|c|}{$[$ Monomer $=\operatorname{TrA}]$} \\
\hline 1 & $\left(\text { iso- } \mathrm{PrOCO}_{2}\right)_{2}$ & 50 & 40 & 24 & 11 & 27 & 1.14 & $0.49: 0.51$ \\
\hline 2 & $n$-BuLi & 20 & -78 & 24 & 49 & 1300 & 4.72 & $0.65: 0.35$ \\
\hline \multicolumn{9}{|c|}{$[$ Monomer $=$ PDBSA $]$} \\
\hline 3 & (iso- $\left.\mathrm{PrOCO}{ }_{2}\right)_{2}$ & 50 & 40 & 24 & 5 & 34 & 1.59 & $0.56: 0.44$ \\
\hline 4 & $n$-BuLi & 20 & 0 & 3 & 67 & 89 & 2.42 & $0.60: 0.40$ \\
\hline 5 & $n$-BuLi & 20 & -78 & 26 & 13 & 112 & 5.40 & $0.51: 0.49$ \\
\hline
\end{tabular}

${ }^{a}[$ Monomer $] /[$ initiator $]$ ratio. ${ }^{b}$ Methanol insoluble part. ${ }^{\mathrm{c}}$ Determined by GPC (polystyrene standard). 
Table II. Polymerization of $\operatorname{TrA}$ and PDBSA in toluene with various chiral initiators at $-78^{\circ} \mathrm{C}$ for $24 \mathrm{~h}^{\mathrm{a}}$

\begin{tabular}{|c|c|c|c|c|c|c|c|}
\hline \multirow{2}{*}{ Entry } & \multirow{2}{*}{ Monomer/Initiator } & \multirow{2}{*}{ Chiral ligand } & Yield $^{\mathrm{b}}$ & \multirow{2}{*}{$\mathrm{DP}_{n}{ }^{\mathrm{c}}$} & \multirow{2}{*}{$M_{w} / M_{n}^{\mathrm{c}}$} & Tacticity & \multirow{2}{*}[\alpha]{$_{365}^{25}$} \\
\hline & & & $\%$ & & & $m: r$ & \\
\hline \multicolumn{8}{|c|}{$\operatorname{TrA} /$} \\
\hline 1 & DPEDA-Li & $(+)-P M P$ & 96 & 46 & 1.28 & $0.70: 0.30$ & $+102^{\circ}$ \\
\hline 2 & & $(-)-S p$ & 98 & 57 & 2.94 & $0.64: 0.36$ & n.d..$^{\mathrm{e}}$ \\
\hline 3 & & $(+)$-DDB & 100 & 61 & 1.38 & $0.49: 0.51$ & $-7^{\circ}$ \\
\hline \multicolumn{8}{|c|}{ PDBSA/ } \\
\hline 4 & FlLi & $(+)$-PMP & 95 & 42 & 1.16 & $0.55: 0.45$ & $\sim 0^{\circ}$ \\
\hline 5 & & $(-)-S p$ & 96 & 41 & 1.60 & $0.54: 0.46$ & $\sim 0^{\circ}$ \\
\hline 6 & & $(+)$-DDP & 95 & 43 & 1.29 & $0.61: 0.39$ & $-72^{\circ}$ \\
\hline 7 & DPEDA-Li & (+)-PMP & 96 & 36 & 1.16 & $0.56: 0.44$ & $+18^{\circ}$ \\
\hline 8 & & $(-)-\mathrm{BMPE}$ & 65 & 34 & 1.11 & $0.52: 0.48$ & $\sim 0^{\circ}$ \\
\hline 9 & & $(-)-S p$ & 96 & 45 & 1.99 & $0.53: 0.47$ & $+4^{\circ}$ \\
\hline 10 & & $(+)$-DDB & 94 & 46 & 1.43 & $0.61: 0.39$ & $-94^{\circ \mathrm{f}}$ \\
\hline
\end{tabular}

${ }^{\mathrm{a}}[$ Monomer $] /[$ Initiator $]=20 .{ }^{\mathrm{b}}$ Methanol insoluble part. ${ }^{\mathrm{c}}$ Determined by GPC (polystyrene standard). ${ }^{\mathrm{d}}$ Measured in $\mathrm{CHCl}_{3}\left(c=c a\right.$. 1). ${ }^{\mathrm{e}}$ Not determined. The obtained polymer was partly insoluble in common organic solvents. ${ }^{\mathrm{f}}[\alpha]_{\mathrm{D}}^{25}=-22.5^{\circ}\left(c=1.0, \mathrm{CHCl}_{3}\right)$.

Table III. Polymerization of PDBSA with (+)-DDB-DPEDA-Li in toluene for $24 \mathrm{~h}^{\mathrm{a}}$ Effects of polymerization temperature

\begin{tabular}{|c|c|c|c|c|c|}
\hline & Temp & Yield $^{\mathbf{b}}$ & & & Tacticity \\
\hline & ${ }^{\circ} \mathrm{C}$ & $\%$ & & & $m: r$ \\
\hline 1 & 0 & 97 & 58 & 1.31 & $0.63: 0.37-103^{\circ}$ \\
\hline 2 & -40 & 97 & 55 & 1.44 & $0.62: 0.38-129^{\circ} \mathrm{e}$ \\
\hline 3 & -78 & 94 & 46 & 1.43 & $0.61: 0.39-94^{\circ}$ \\
\hline
\end{tabular}

${ }^{\mathrm{a}}[\mathrm{PDBSA}] /[$ Initiator $]=20 .{ }^{\mathrm{b}}$ Methanol insoluble part. ${ }^{\mathrm{c}}$ Determined by GPC (polystyrene standard). ${ }^{\mathrm{d}}$ Measured in $\mathrm{CHCl}_{3} \cdot{ }^{\mathrm{e}}[\alpha]_{\mathrm{D}}^{25}=-27^{\circ}\left(c=1.05, \mathrm{CHCl}_{3}\right)$.

possessing the highest negative specific rotation $\left([\alpha]_{365}^{25}=-129^{\circ}\right.$ in $\left.\mathrm{CHCl}_{3}\right)$ was obtained by polymerization at $-40^{\circ} \mathrm{C}$, although the effect of temperature on tacticity was hardly observed.

Influence of the ratio of monomer to initiator $([\mathrm{M}] /[\mathrm{I}])$ in the polymerization at $-78^{\circ} \mathrm{C}$ is summarized in Table IV. The isotacticity and specific rotation of the obtained polymers clearly increased with the degree of polymerization $\left(\mathrm{DP}_{n}\right)$, apparently reaching a plateau value around $[\mathrm{M}] /[\mathrm{I}] \geq 20$.

The polymerization of PDBSA with the
Table IV. Polymerization of PDBSA with (+)-DDB-DPEDA-Li in toluene at $-78^{\circ} \mathrm{C}^{\mathrm{a}}$ Effects of [PDBSA $] /[$ Initiator] ratio

\begin{tabular}{|c|c|c|c|c|c|c|}
\hline \multirow{2}{*}{\multicolumn{2}{|c|}{ Entry $[\mathrm{M}] /[\mathrm{I}]^{\mathrm{b}}$}} & Yield $^{c}$ & & & Tacticity & \multirow{2}{*}[\alpha]{$_{365}^{25}{ }^{e}$} \\
\hline & & $\%$ & $\mathrm{DP}_{n}{ }^{\mathrm{d}}$ & $M_{w} / M_{n}{ }^{d}$ & $m: r$ & \\
\hline 1 & 5 & 85 & 22 & 1.08 & $0.41: 0.59$ & $-31^{\circ}$ \\
\hline 2 & 10 & 94 & 34 & 1.16 & $0.55: 0.45$ & $-48^{\circ}$ \\
\hline $3^{f}$ & 20 & 94 & 46 & 1.43 & $0.61: 0.39$ & $-94^{\circ}$ \\
\hline 4 & 40 & 79 & 56 & 1.66 & $0.61: 0.39$ & $-104^{\circ}$ \\
\hline
\end{tabular}

${ }^{a}$ Polymerization time, $48 \mathrm{~h}$. ${ }^{\mathrm{b}}$ Ratio of monomer (PDBSA) to initiator ((+)-DDB-DPEDA-Li). ${ }^{\mathrm{c}}$ Methanol insoluble part. ${ }^{\mathrm{d}}$ Determined by GPC (polystyrene standard). ${ }^{\mathrm{e}}$ Measured in $\mathrm{CHCl}_{3}$. ${ }^{\mathrm{f}}$ Polymerization time, $24 \mathrm{~h}$.

(+)-DDB-DPEDA-Li system was also carried out in a $1.0-\mathrm{cm}$ optical cell in toluene at $-78^{\circ} \mathrm{C}$ and change in optical rotation of the reaction mixture was directly followed. The results are shown in Figure 1. The optical rotation gradually increased in a negative direction as polymerization proceeded. After about $20 \mathrm{~h}$, the specific rotation $[\alpha]_{435}^{-78}$ of the polymer reached about $-42^{\circ}$. These results suggest that the optical activity of poly(PDBSA) may not be due to the chirality in the vicinity of chain 
end as observed for the optically active poly $(\operatorname{TrA}){ }^{4}$

The obtained (-)-poly(PDBSA) (entry 10 in Table II) was analyzed by GPC equipped with UV and polarimetric detectors (Figure 2). UV detection indicates that the polymer included small amounts of high and low molecular weight fractions and the pattern of the main fraction is similar to that of the polarimetric detection, suggesting that the whole polymer including high molecular weight parts is optically active.

The circular dichroism (CD) spectra of (-)-poly(PDBSA)s are shown in Figure 3. The

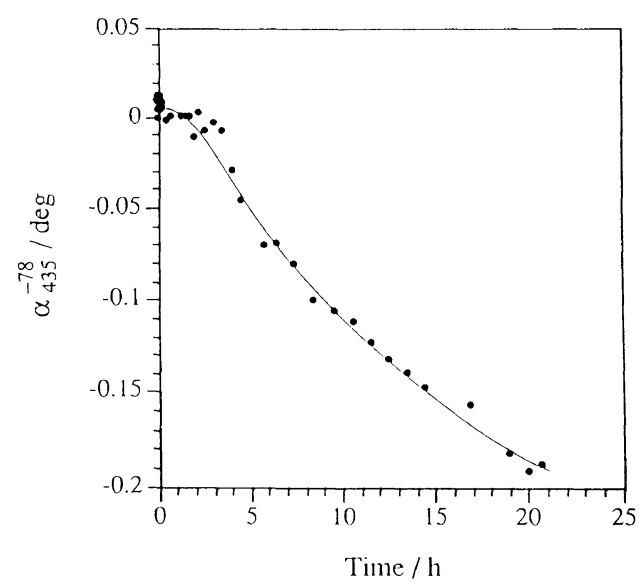

Figure 1. Change of optical activity during the polymerization of PDBSA by (+)-DDB-DPEDA-Li system in toluene at $-78^{\circ} \mathrm{C}$ in a $1.0-\mathrm{cm}$ cell.

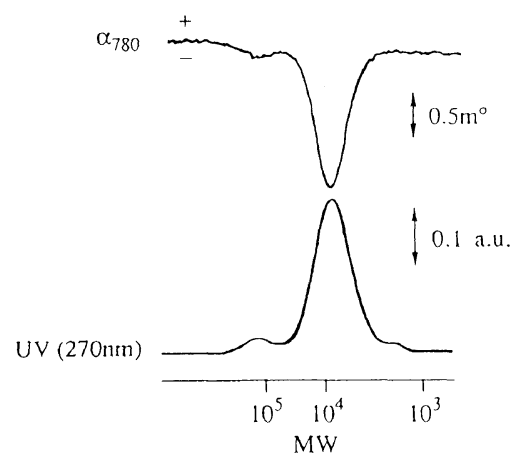

Figure 2. GPC curves of poly(PDBSA) obtained with (+)-DDB-DPEDA-Li in toluene at $-78^{\circ} \mathrm{C}$ (detector: UV and polarimeter). spectra demonstrate the negative peaks at $207 \mathrm{~nm}$ and $230 \mathrm{~nm}$ which may be ascribed to the absorption due to the aromatic and carbonyl groups, respectively. The absorption intensity clearly rises with increase of the degree of specific rotation. These spectral patterns are quite similar to those of the one-handed helical, optically active poly(TrMA $)^{2 b}$ and optically active poly(TrA). ${ }^{4}$ The results shown above indicate that a partially helical structure must be introduced throughout the polymer chain.

The conformational stability of (-)-poly(PDBSA) $\left([\alpha]_{365}^{25}=-94^{\circ}\right.$ in $\left.\mathrm{CHCl}_{3}\right)$ was investigated in $\mathrm{CHCl}_{3}$ at $60^{\circ} \mathrm{C}$ (Figure 4). The optical activity $\left(\alpha_{365}^{60}=-0.18\right)$ gradually decreased with time and reached about -0.13 after $120 \mathrm{~min}$, and then the solution became turbid. This behavior in chloroform is different from that of $(+)$-poly(TrA) (entry 1 in Table II), which precipitated immediately after the dissolution in chloroform. ${ }^{4}$ The results indicate that the optically active poly(PDBSA) is not conformationally stable, and some conformational changes and association occur in $\mathrm{CHCl}_{3}$

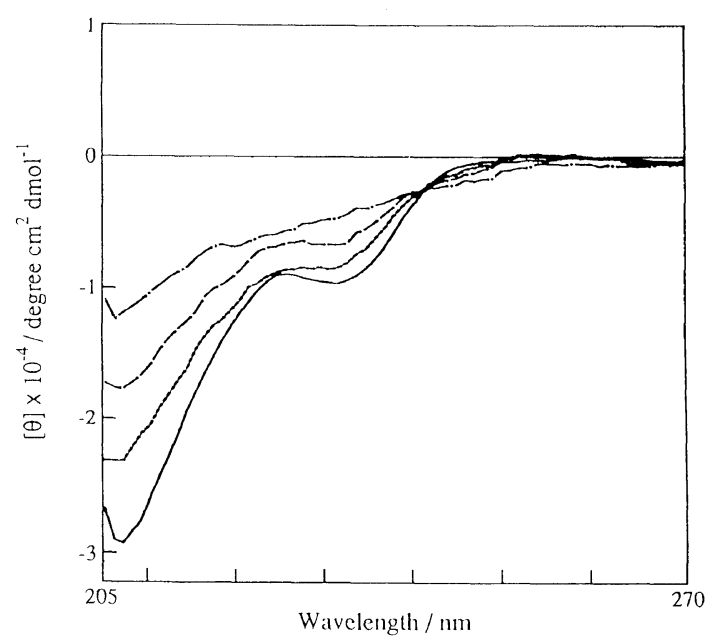

Figure 3. CD spectra of (-)-poly(PDBSA) obtained with (+)-DDB-DPEDA-Li in toluene (solvent: THF). $-, \quad-40^{\circ} \mathrm{C},[\mathrm{M}] /[\mathrm{I}]=20\left([\alpha]_{365}^{25}=-129^{\circ}\right) ; \cdots-\cdots$, $-78^{\circ} \mathrm{C},[\mathrm{M}] /[\mathrm{I}]=40\left([\alpha]_{365}^{25}=-104^{\circ}\right) ;---,-78^{\circ} \mathrm{C}$, $[\mathrm{M}] /[\mathrm{I}]=20\left([\alpha]_{365}^{25}=-94^{\circ}\right) ; \cdot \cdots \cdot \cdot,-78^{\circ} \mathrm{C},[\mathrm{M}] /[\mathrm{I}]=$ $10\left([\alpha]_{365}^{25}=-48^{\circ}\right)$. 


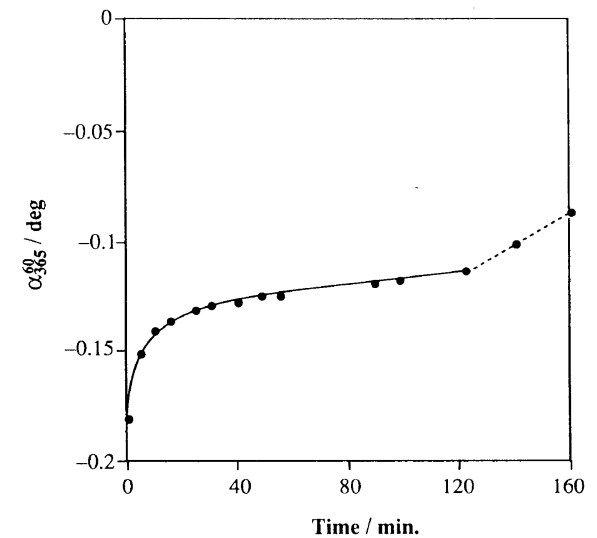

Figure 4. Change of optical rotation of (-)-poly(PDBSA) $\left([\alpha]_{365}^{25}=-94^{\circ}\right)$ in $\mathrm{CHCl}_{3}$ at $60^{\circ} \mathrm{C}$.

at $60^{\circ} \mathrm{C}$.

In conclusion, the polymerization of PDBSA was greatly influenced by chiral initiator systems, and (+)-DDB complexes were most effective for obtaining the polymer with high optical activity. The bulky ester group, 1phenyldibenzosuberyl-group did not induce highly isotactic specific polymerization for acrylic esters in either anionic or radical polymerization. The obtained poly(PDBSA)s are optically active which is mainly ascribed to conformation. The isotactic part in the polymer probably has a helical conformation which contributes to optical activity.

Acknowledgment. This work was partly supported by a Grant-in-Aid for Scientific Research (No. 04403021) from the Ministry of Education, Science, and Culture of Japan.

\section{REFERENCES AND NOTES}

1. For review, see: a) G. Wulff, Angew. Chem., Int. Ed. Engl., 28, 21 (1989). b) Y. Okamoto and T. Nakano, Chem. Rev., 94, 349 (1994).

2. a) Y. Okamoto, K. Suzuki, K. Ohta, K. Hatada, and H. Yuki, J. Am. Chem. Soc., 101, 4763 (1979). b) Y. Okamoto, K. Suzuki, and H. Yuki, J. Polym. Sci., Polym. Chem. Ed., 18, 3043 (1980). c) Y. Okamoto, H. Shohi, and H. Yuki, J. Polym. Sci., Polym. Lett. Ed., 21, 601 (1983). d) G. Wulff, R. Sczepan, and A. Steigel, Tetrahedron Lett., 27, 1991 (1986). e) Y. Okamoto, E. Yashima, T. Nakano, and K. Hatada, Chem. Lett., 759 (1987). f) T. Nakano, Y. Okamoto, and K. Hatada, J. Am. Chem. Soc., 114, 1318 (1992).

3. a) H. Yuki, Y. Okamoto, and I. Okamoto, J. Am. Chem. Soc., 102, 6358 (1980). b) Y. Okamoto, S. Honda, I. Okamoto, H. Yuki, S. Murata, R. Noyori, and H. Takaya, J. Am. Chem. Soc., 103, 6971 (1981). c) Y. Okamoto, S. Honda, K. Hatada, and H. Yuki, J. Chromatogr., 350, 127 (1985). d) Y. Okamoto and K. Hatada, J. Liq. Chromatogr., 9, 369 (1986).

4. S. Habaue, T. Tanaka, and Y. Okamoto, Macromolecules, 28, 5973 (1995).

5. T. Nakano, M. Mori, and Y. Okamoto, Macromolecules, 26, 867 (1993).

6. L. Colombo, C. Gennari, G. Poli, and C. Scolastico, Tetrahedron, 101, 2725 (1982).

7. a) K. Matsuzaki, T. Uryu, and A. Ishida, J. Polym. Sci., Part A, 5, 2167 (1967). b) T. Suzuki, E. R. Santee, Jr., H. J. Harwood, O. Vogl, and T. Tanaka, J. Polym. Sci., Polym. Lett. Ed., 12, 635 (1974).

8. The isomerization of stereogenic center does not seem to occur during the conversion of PDBSA to PMA, because when poly(methyl acrylate) $(m=0.90)$ was treated in the same manner as performed for PDBSA, the recovered poly(methyl acrylate) had the same isotacticity $(m=0.89)$.

9. K. Matsuzaki, T. Uryu, T. Kanai, K. Hosonuma, T. Matsubara, H. Tachikawa, M. Yamada, and S. Okuzono, Makromol. Chem., 178, 11 (1977). 